\title{
PESSOA SURDA E AUTONOMIA FREIREANA: \\ O CIBERESPAÇO COMO MEIO DE SOERGUIMENTO
}

DEAF PERSON AND FREIREAN AUTONOMY:

CYBERSPACE AS A MEANS OF SURVIVAL

PERSONA SORDA Y AUTONOMÍA FREIREANA:

EL CIBERESPACIO COMO MEDIO DE SUPERVIVENCIA

Jéssica Bittencourt França ${ }^{1}$
Rodrigo Pedro Casteleira

\begin{abstract}
RESUMO
Este trabalho pretende expor, ainda que de modo teórico, as possibilidades para a interação, autonomia e disseminação da Língua Brasileira de Sinais (LIBRAS) da comunidade surda tendo como intermédio os ciberespaços ou a geografia virtual. Estes entendidos como os meios de acesso às redes de internet que facilitam essa interação com um universo sócio-virtual, sem enfatizar a surdez. Esse livre acesso às redes possibilita aos surdos a possibilidade de comunicação, expressão, retenção de informações, aprendizagem e contato com o mundo externo sem precisar necessariamente do auxílio de uma terceira pessoa ouvinte nesse processo, o que permite maior privacidade e mesmo a autonomia. A autonomia refere-se ao conceito freirenano, por entendermos que ele pode ser um marcador pontual para pensar uma educação não inclusiva, mas mais democrática e de posicionamento de práticas educativas como prática de liberdade.
\end{abstract}

PALAVRAS-CHAVE: Autonomia. Paulo Freire. Geografia virtual. Comunidade surda.

\section{ABSTRACT}

This work intends to expose, albeit in a theoretical way, the possibilities for interaction, autonomy and dissemination of the Brazilian Sign Language (LIBRAS) of the deaf community using cyberspace or virtual geography as an intermediary. These are understood as the means of access to internet networks that facilitate this interaction with a socio-virtual universe, without emphasizing deafness. This free access to networks allows deaf people the possibility of communication, expression, information retention, learning and contact with the outside world without necessarily needing the help of a third person who listens in this process, which allows greater privacy and even autonomy. Autonomy refers to the Freirene concept, as we understand that it can be a punctual marker for thinking about a non-inclusive education, but more democratic and for the positioning of educational practices as a practice of freedom.

KEYWORDS: Autonomy. Paulo Freire. Virtual geography. Deaf community.

Submetido em: 28/05/2021 - Aceito em: 05/10/2021 - Publicado em: 13/10/2021

1 Acadêmica de pedagogia pela Universidade Federal de Rondônia (UNIR), campus de Vilhena, RO.

2 Doutor em educação, professor do Departamento Acadêmico de Ciências da Educação da Fundação Universidade Federal de Rondônia (UNIR), no campus de Vilhena, RO. 


\section{RESUMEN}

Este trabajo pretende exponer, aunque de manera teórica, las posibilidades de interacción, autonomía y difusión de la Lengua de Signos Brasileña (LIBRAS) de la comunidad sorda utilizando el ciberespacio o la geografía virtual como intermediario. Estos se entienden como los medios de acceso a las redes de internet que facilitan esta interacción con un universo socio-virtual, sin enfatizar la sordera. Este libre acceso a las redes permite a las personas sordas la posibilidad de comunicarse, expresarse, retener información, aprender y contactar con el mundo exterior sin necesitar necesariamente la ayuda de una tercera persona que escuche en este proceso, lo que permite una mayor privacidad e incluso autonomía. La autonomía se refiere al concepto Freirene, pues entendemos que puede ser un marcador puntual para pensar en una educación no inclusiva, pero más democrática y para el posicionamiento de las prácticas educativas como práctica de libertad.

PALABRAS CLAVE: Autonomía. Paulo Freire. Geografía virtual. Comunidad de sordos.

\section{INTRODUÇÃO}

O assunto principal a ser discutido nesta escrita refere-se aos entrecruzamentos sobre comunidade surda, geografia virtual, aqui articulada como ciberespaço, e a possibilidade de comunicação para a autonomia do sujeito (surdo), conforme conceituações freireanas. Nosso objetivo não é o do aprofundamento na contextualização da surdez, mas analisar a importância da comunicação e interação social da pessoa surda nas/pelas redes virtuais com um meio facilitador, sem, necessariamente, depender de uma pessoa como intermediária. A articulação desta escrita, ainda, entremeia-se junto ao campo educacional para além do formal, constituindo tensões: entre as pessoas que aqui escrevem por serem ouvintes; o campo geográfico virtual e a possibilidade de acesso e comunicabilidade entre pessoas surdas; e uma educação para autonomia junto aos usos de ferramentas virtuais para a comunicação.

O conceito de autonomia, conceituado por Freire (1996) em sua obra "Pedagogia da autonomia", "rediscute a questão da necessidade de se compreender a educação em sua politicidade e historicidade" (ALBURQUERQUE, 2018, p. 2015) e a tomamos exatamente para questionar os campos da politicidade e historicidade vivenciados pela comunidade surda no Brasil, sobretudo junto a dispositivos legais de regulamentação e oficialização da Língua Brasileira de Sinais (LIBRAS). Esses questionamentos vão no sentido de pensar os descompassados entre o direito à educação no Brasil e a regulamentação da LIBRAS, ocorrida apenas em 2002, o que parece revelar uma política oriunda do Estado sem o reconhecimento histórico da comunidade surda como detentora do direito à educação.

Mesmo sob esses descompassos e vivendo em uma comunidade ouvinte-centrada, o advento de tecnologias virtuais trouxe possibilidades de uma maior autonomia social via redes da internet. A pessoa surda, juntamente com sua comunidade surda, adquire inúmeras informações e ajuda a expandir a LIBRAS por intermédio de compartilhamento de vídeos e outros materiais no universo do hipertexto, o que gera alcances inimagináveis e possibilita uma maior socialização entre pessoas surdas e não surdas. $\mathrm{O}$ espaço virtual propiciaria, deste 
modo, contatos outros espaços e, potencialmente, retiraria a configuração de isolamento da pessoa surda imersa em um mundo de maioria ouvinte.

Como modo de organizar este trabalho, utilizamos uma abordagem descrita como qualitativa (COSTA et at., 2005) a fim de dar contornos às nossas categorias, a saber, comunidade surda, comunicação, educação e autonomia, isso tudo imbuído pelo que chamamos de geografia virtual, ou ciberespaços. Utilizamos os conceitos freireanos de educação para autonomia, tanto presente em sua obra Pedagogia da autonomia como em outras discutidas por Albuquerque (2018), bell hooks (2017) - grafado assim por solicitação da própria autora - e Souza (2018). Nesse interim, dialogamos, ainda, sob a definição de ciberespaços junto de Pierre Lévy (1999) somada às breves definição da pessoa surda e sua língua, aqui discutidas junto de Marcia Honora (2014), a Lei no 10.436 de abril de 2002 e o Decreto $n^{\circ} 5.626$ de dezembro de 2005, além de Andreoli, Vieira e Campos (2013), com a discussão da importância da interação para pensar a pessoa surda frente à existência de um ambiente virtual e as ferramentas dispostas nele para o acesso à comunicação e à educação formal.

Os conceitos freireanos importam, para nossas problematizações, exatamente por tensionarem o multiculturalismo presente na realidade da materialidade humana das pessoas que acessam o sistema educacional formal. Para essa relação ganhar um corpus e práxis, a formação do professorado precisa, também, estar em consonância com a proposição de "criar estratégias para abordar a sala de aula e o currículo multiculturalismo" (bell hooks, 2017, p. 52). A pensadora bell hooks (2017), na esteira das concepções freireanas, chama a atenção para o posicionamento não neutro no espaço político da educação, sobretudo quando observamos a manutenção do status quo na academia e os corpos que nela trafegam. Ainda que Freire (1996) e bell hooks (2017) não tenham discutido a inserção da comunidade surda nos espaços acadêmicos, a inferência é mais do que possível frente às relações acerca do multiculturalismo:

O multiculturalismo obriga os educadores a reconhecer as estreitas fronteiras que moldaram o modo como o conhecimento é partilhado na sala de aula. Obriga todos nós a reconhecer nossa cumplicidade na aceitação e perpetuação de todos os tipos de parcialidade e preconceito. (bell hooks, 2017, p. 63).

O processo de moldar esse 'como' está intimamente ligado às relações não apenas de classe, gênero, racialidade e localidade, mas também no que tocante às pessoas com deficiência: pessoas cegas, surdas, cadeirantes etc. Se a educação toma por paradigma a manutenção de um público específico no interior da academia, falha, sobremaneira, no campo democrático, por isso, nas palavras de Freire (1996, p. 39), na "formação permanente de professores, o momento fundamental é o da reflexão crítica sobre a prática. É pensando criticamente a prática de hoje ou de ontem que se pode melhorar a próxima prática."

Deste modo, pensar em uma geografia virtual como campo para estreitar a comunicação junto de pessoas surdas, a fim da efetivação do processo democrático na educação (acesso e permanência) torna-se pertinente. Sobretudo, ao (re)pensarmos na assunção de nossa existência, segundo Freire (1996), que não representa o apartamento das outras existências, 
mas a possibilidade de uma solidariedade política e social sob o objetivo de construir uma sociedade menos desigual.

Essa geografia virtual, em certa medida, opõe-se ao conceito de suporte, discutido por Freire (1996), a saber, uma reunião de aparatos capazes de dar condições para a vida de uma espécie. Diferente dos demais animais, a espécie humana se torna dependente de constructos históricos e culturais criados por ela mesmo, substituindo o suporte por fazer-se mundo. Essa dependência gera uma humanidade inacabada, cria a existência, a vida, no fazer-se mundo, na "proporção que o corpo humano vira corpo consciente, captador, apreendedor, transformador, criador de beleza e não "espaço" vazio a ser preenchido por conteúdos" (FREIRE, 1996, p. 51). A interferência humana no suporte demandou a criação da linguagem para nomear as coisas, ao mesmo tempo em que implicou na inteligibilidade na comunicação, no existir e assumir um posicionamento no mundo pela construção da política. Hoje, a comunicação também se faz, e nos faz, pela via da virtualidade, contudo, nem todas as pessoas parecem agregadas ao ciberespaço, ou que o não parece construído para que toda e qualquer pessoa o acesse, como pessoas surdas.

\section{DEFINIÇÃO DE CIBERESPAÇOS}

A fim de pensarmos em possibilidades democráticas e de um exercício da autonomia no campo da educação, o que usamos como sinônimo o termo soerguimento, trazemos algumas possibilidades existentes no campo dos ciberespaços, como as ferramentas da/na virtualidade. Antes de nos determos em descrever algumas ferramentas, conceituaremos um pouco acerca da compreensão de ciberespaço.

Os ciberespaços podem ser definidos como sítios de utilização pública e/ou privada de comunicação, informação, cultura e entretenimento, abarcando outras extensões mundiais, graças à sua capilaridade e gradativa expansão. Resumidamente, o ciberespaço poderia ser definido como "o espaço de comunicação aberto pela interconexão mundial dos computadores" (LÉVY, 1999, p. 92). O surgimento da terminologia 'ciberespaço', que por vezes também usamos no plural, é observado no livro "Neuromante", grafado pelo escritor norte-americano Willian Gibson, em 1984. Nessa obra ficcional, o contexto da palavra aparece como universo das redes digitais, e não é nossa intenção discutir sua origem dentro do trabalho de Gibson, mas os desdobramentos possíveis sob a via de Lévy (1999), por exemplo, somadas aos vínculos dentro/fora da educação formal, para depois associarmos à comunidade surda. Levy (1999), por sua vez, o descreve o que entende por ciberespaço e sua relação com a comunicação:

O ciberespaço (que também chamarei de "rede") é o novo meio de comunicação que surge da interconexão mundial dos computadores. O termo especifica não apenas a infraestrutura material da comunicação digital, mas também o universo oceânico de 
informações que ela abriga, assim como os seres humanos que navegam e alimentam esse universo. (LÉVY, 1999, p. 15)

A utilização desse espaço oceânico, alimentável e alimentado, é de privilégio do acesso às redes de internet, "que transitam em servidores e terminais conectados" (FRAGOSO, 2003, p. 2). Por causa dessa fluidez, essa rede é de difícil mensuração de uma localização certa em um espaço físico, devido a seu grande e rápido avanço e crescimento. Além disso, milhares de pessoas utilizam as capilaridades existentes em busca de informações, sensações imediatistas, entretenimento, militâncias, trabalho, educação, para citar alguns exemplos, sem se preocupar especificamente com a geografia dos acessos, pois, conforme afirma Lévy (1999, p. 93), "uma das principais funções do ciberespaço é o acesso a distância dos diversos recursos de um computador".

Essa geografia virtual - aqui pensamos enquanto um campo virtual de mobilidades - parece desvinculada da geografia física exatamente pelos processos conectivos e de acessos à virtualidade, quase que criando um deslocamento entre a materialidade do sujeito que acessa e sua existência virtual conectada como, por exemplo, hipoteticamente pensar em pessoas com perfis diversos de suas próprias existências: outras classes, outros gêneros, outras localidades etc. Por outro lado, essa geografia virtual propiciaria ferramentas para resolver problemáticas de comunicação: mensagens de voz enviadas por pessoas não alfabetizadas, uma vez que podem não saber ler e escrever com fluidez; ou mensagens de textos e usos de aplicativos de tradução da LIBRAS para criar uma comunicação mais efetiva entre comunidade surda e ouvinte, pensando aqui na comunidade surda letrada em LIBRAS, entre outras possibilidades.

A geografia virtual, desse modo, extrapola com a dinâmica da presença materializada ao lado de, mas contempla as presenças virtuais entre, agregando uma heterogeneidade de pessoas, classes, idades, existências, dispostas em rede e unidas sob o objetivo consono à produção de comunicação virtual. As bases comunicacionais entre quem comunica e quem recebe agora são arquitetadas nos terrenos de plataformas como facebook, instagram, whatsapp, demais aplicativos, sites de pesquisas, youtube, google, entre outros existentes e outros vindouros. Não se trata de estabelecer uma relação de repúdio ou endeusamento às tecnologias desse tipo, sobretudo porque é uma "forma altamente negativa e perigosa de pensar errado" (FREIRE, 1996, p. 33).

A tarefa de quem educa, ainda na argumentação de Freire (1996), consiste em desafiar quem é educado(a), com quem se comunica. Todavia, para existir uma inteligibilidade comunicativa, o processo comunicacional precisa ser efetivado e, ao pensar na comunidade surda imersa em uma sociedade ouvinte, talvez os ciberespaços possam oferecer ferramentas para que esse processo ocorra. Ao pensar como esses ciberespaços vinculam-se ao nomadismo e descentralização, não podemos esquecer a zona de 'contato' existente entre o mundo virtual e o físico, conceituado como espacialidade híbrida (virtual e urbano) (PEREIRA; PERLIN, 2016). 
O espaço híbrido, desse modo, forneceria condições positivas para que a comunidade surda estabeleça seus processos comunicativos. A pessoa surda, na materialidade desse hibridismo acessaria determinado equipamento físico (celular, computadores) para acessar o mundo virtual, firmar conexões com outras pessoas, informar-se etc. Nessa dinâmica junto das tecnologias digitais, a comunidade surda também aprende e anseia pela comunicação ampla, seja entre pessoas surdas.

Os sujeitos surdos também compartilham dessa urgência interativa, tanto pela coletividade surda (encontro com seus pares) quanto pelo contato com os ouvintes, pois a convergência midiática possibilita a veiculação de uma pluralidade de sistemas sígnicos. (PEREIRA; PERLIN, 2016)

A urgência pela comunicação e inserção na geografia virtual suscita, a nosso ver, dois movimentos: o primeiro o da comunidade surda pela comunicação via ciberespaços e o segundo, a oferta nos ciberespaços de ferramentas capazes de promover a comunicabilidade. Essa realidade, ao ser estudada de modo aprofundado e junto do engajamento político, é capaz de revelar a "relação orgânica dos homens entre si e com seu meio, contraditória, é o substrato da práxis social, por meio da qual o homem faz história e cria o mundo da cultura" (SOUZA, 2015, 42). A autora, guiando-se pelos estudos freireanos, nos dá indícios para pensarmos sobre esses processos vivenciados por sujeitos surdos envoltos pelas tecnologias dispostas pelo ciberespaço, ao mesmo tempo em que seja uma relação contraditória, é capaz de significar-se no mundo e criar um universo cultural.

\section{PESSOA SURDA E SUA LÍNGUA}

Antes de entremearmos mais os atravessamentos sobre o conceito de autonomia freireana, faz-se necessário dimensionar, minimamente, a categorização da pessoa surda e surdez. A surdez, segundo Márcia Honora (2014), é o impedimento da capacidade auditiva de compreensão de sons, com a utilização ou não de Aparelhos de Amplificação Sonora Individual. Ao mirarmos para os dispositivos legais, conforme o Decreto $n^{\circ} 5.626$ de 22 de dezembro de 2005, perceberemos que:

Art. $2^{\text {o: }}$ Para fins desse Decreto, considera-se pessoa surda aquela que, por ter perda auditiva, compreende e interage com o mundo por meio de experiências visuais, manifestando sua cultura principalmente pelo uso da Língua Brasileira de Sinais - LIBRAS. (BRASIL, 2005)

De um ponto de vista clínico a surdez parece ser vista como um problema a ser solucionado, como se houvesse a necessidade pela busca da correção por parte da pessoa surda afim de que se enquadre na definição de "normal". Essas insistências se perpetuaram ao longo da história a ponto de observarmos que "no processo de classificar o que é normal, é que a modernidade, com a liberação das ciências da vida, inventa o surdo, o cego, o louco tanto como objetos de estudos como de intervenções - clínicas, assistenciais, jurídicas e legais [...]" (PERLIN; SOUZA, 2015, p. 54), em busca de uma solução ao "problema" e/ou uma igualdade, onde de 
um ponto de vista médico visa-se olhar para a pessoa surda na procura de meios de igualá-la à comunidade ouvinte. O Decreto supracitado vai de encontro com esse posicionamento de correção para adequação à normalidade, sobretudo quando o dispositivo legal afirma e legitima a cultura surda e a sua comunicação pelas experiencias visuais e/ou o uso da LIBRAS.

Para a pessoa surda não há existência de deficiência e não se considera pessoa com menos potencial, e sim, pessoa surda capaz, por exemplo, de se comunicar pela LIBRAS, de acessar informação, também com capacidade igual a qualquer pessoa dita "normal". A ideia de normalidade gerou termos pejorativos e frente a todo corpo pensado como fora dela, no caso da pessoa surda, termos como Surdo-Mudo, Surdinho, deficiente, especial, excepcional só revelam as assimetrias de poder entre a comunidade ouvinte e a surda. Como expressa Laborrit (apud GESSER 1971, p. 46), "recuso-me a ser considerada excepcional, deficiente. Não sou. Sou surda. Para mim, a língua de sinais corresponde à minha voz, meus olhos são meus ouvidos. Sinceramente nada me falta, é a sociedade que me torna excepcional". A afirmação revela a perspectiva vivenciada por uma pessoa surda envolta em uma comunidade ouvinte ao mesmo tempo em que realiza uma leitura crítica de mundo (ALBURQUEQUE, 2015). Assumir-se como pessoa surda, pertencente a uma comunidade surda, é assumir-se como sujeito "capaz de reconhecer-se como objeto" (FREIRE, 1996, p. 41) sem, com isso, excluir ouras existência no momento da própria assunção. Reconhecer tanto a dimensão de classe como a dimensão identitária do sujeito torna-se fundamento para uma prática educativa progressista.

Apesar da existência histórica dessas pessoas, apenas em 2002 o Estado as reconhece e oficializa a LIBRAS como língua específica de comunicação para comunidade surda, como podemos observar na Lei Federal $n^{\circ} .10 .436$, de 24 de abril de 2002, em seu art. $1^{\circ}$ é possível ler sobre seu reconhecimento legal e gramatical:

É reconhecida como meio legal de comunicação e expressão a Língua Brasileira de Sinais - LIBRAS e outros recursos de expressão a ela associados.

Parágrafo único. Entende-se como Língua Brasileira de Sinais - LIBRAS a forma de comunicação e expressão, em que o sistema linguístico de natureza visual-motora, com estrutura gramatical própria, constituem um sistema linguístico de transmissão de ideias e fatos, oriundos de comunidades de pessoas surdas do Brasil. (BRASIL, 2002)

A oficialização da LIBRAS pelo Estado merece ser citada, mas não significa, com isso, que o meio ouvinte tenha aderido a ela ou à compreensão de uma leitura crítica de mundo sobre sua necessidade, conforme aponta Albuquerque (2015), ou mesmo que o Estado propiciou a prática educativa progressista (FREIRE, 1996). Ao pensarmos nesse recorte de tempo da promulgação da lei, quais os descompassos vividos pelas pessoas surdas quando o assunto é a educação formal? Se, como defende Albuquerque (2015) junto de Freire (1996), "somos presença no mundo, com o mundo e com os outros" (ALBUQUERQUE, 2015, p. 209), a 
educação formal, via Estado, parece ter ignorado essas presenças surdas todas por muitos anos, logo, o processo por uma educação para a autonomia não tinha espaço para sua efetivação.

É com a LIBRAS que a pessoa surda, alfabetizada por ela, compreende o mundo e se comunica, tendo-a como principal recurso. Talvez seja essa uma das grandes dificuldades, barreira e até mesmo o impedimento para o recebimento e transmissão de novas mensagens para/com a grande maioria dos ambientes frequentados por pessoas surdas, tais como escolas, hospitais, lojas, trabalho, entre outros. Como a língua predominante e oficial do nosso país é a Língua Portuguesa, isso exige da pessoa surda o conhecimento de ambas para seu próprio desenvolvimento na sociedade e na compreensão dos signos que a cerca. A não assimilação das regras da Língua Portuguesa, gera problemas ao longo de sua escolarização uma vez que há perda de informações e restrições ao acesso a um ensino de qualidade.

\section{PESSOAS SURDAS EM AVOLUMAMENTO NOS CIBERESPAÇOS}

O avanço tecnológico no campo virtual como ferramentas, aplicativos, velocidade de internet etc, vem se multiplicando ao longo dos anos junto do avanço científico aplicados aos sistemas de informática, podendo ser observado com facilidade o desenvolvimento dos aparelhos celulares, que atualmente possuem tecnologias a ponto de serem comparados a minicomputadores. Os processos de mudanças das interfaces dos programas e de toda estrutura material, segundo Pierre Lévy (1999), permitiu a melhoria e diversificação da comunicabilidade. Partindo dessa afirmação, algumas pesquisas, segundo o mesmo autor, discutem a 'realidade ampliada', uma manifestação tecnológica amalgamada entre mundo cibernético e 'real'.

nosso ambiente físico natural é coalhado de sensores, câmeras, projetores de vídeo, módulos inteligentes, que se comunicam e estão interconectados a nosso serviço. Não estamos mais nos relacionando com um computador por meio de uma interface, e sim executamos diversas tarefas em um ambiente "natural" que nos fornece sob demanda os diferentes recursos de criação, informação e comunicação dos quais precisamos. (LÉVY, 1999, p. 37)

Essa miríade de recursos cria uma espécie de extensão protética de quem os utiliza, no caso das pessoas surdas torna-se um recurso comunicativo de uma realidade ampliada capaz de intercomunicação com outras pessoas surdas, por exemplo, sem a necessidade de digitar, mas valendo-se especificamente da LIBRAS (considerando aqui um recorte específico entre pessoas que saibam LIBRAS), em vídeo chamadas disponíveis em diversos aplicativos de redes sociais.

O ciberespaço proporcionar às pessoas usuárias os mais diversos acessos às redes e isso torna possível interações mundiais que extrapolam as fronteiras de tempo e espaço, implicando nos contatos e atravessamentos entre variadas culturas. Esses atravessamentos podem ser 
observados por meio de textos, vídeos, áudios, entre outros recursos, definido como "hipertextos", que são softwares interativos (LÉVY, 1999).

Sob os usos desses equipamentos de interação e tecnologias digitais a comunidade surda expande e amplia o exercício de sua cidadania, "favorecendo sua participação social, por meio da comunicação online, facilitada pela Internet" (ANDRIOLI; VIEIRA; CAMPOS, 2013, p. 1793). Ao mesmo tempo em que as tecnologias mudam, a LIBRAS parece se valer dessas mudanças para sua potencialização de espraiar-se como língua para além dos territórios físicos. As ferramentas virtuais facilitam encontrar materiais que possibilitam a disseminação da língua, dando mais oportunidades de comunicação para a comunidade surda por auxílios tecnológicos. Esse movimento estreita as relações na/da comunidade surda exatamente porque ela não é composta apenas por pessoas surdas, mas também "sujeitos ouvintes - membros de família, intérpretes, professores, amigos e outros - que participam e compartilham interesses comuns em uma determinada localização" (STROBEL, 2018, p. 38).

Qualquer pessoa pode, com auxílio de aplicativos (whatsapp, youtube, facebook, instagram e outros), utilizar hipertextos em sincronismo no universo do Metaverse. Esse universo age como simulacro da realidade com suas vias todas, construções virtuais e tráfegos, além de ser "uma fonte poderosa de entretenimento e educação e também o meio prioritário para a comunicação e o comércio [...]" (AICHELE Apud FRAGOSO, 2003, p. 15). Assim, os canais já mencionados são definidos como produtos criados nesse Metaverse objetivando a facilitação da convivência virtual/espacial.

Nessa perspectiva, a geografia virtual é favorável para a comunicação da comunidade surda, promovendo encontros sociais, aquisição de novos saberes e ramificação de sua língua. As tecnologias digitais "permitem aos surdos, assim como aos ouvintes, introduzirem-se, espontaneamente, na língua que estão usando para se comunicar [...] tenham a oportunidade de interagir e aprender, independente de sua condição física" (ARCOVERDE, 2006, p. 257).

Uma das principais importâncias para as pessoas surdas é a saída do isolamento de informação junto da possibilidade de maior autonomia social, cultural e linguística dentro de sua comunidade e até mesmo na comunidade predominante de ouvintes. Ao propiciar a efetivação da comunicação na comunidade surda, o exercício crítico para o aprender ganha mais possibilidade, sobretudo se pensarmos que uma curiosidade epistemológica (ALBUQUERQUE, 2015), seu desenvolvimento e construção dependam de condições para isso, como a própria comunicação. Ainda que a geografia virtual não priorize a comunicação que não seja primeiro a da comunidade ouvinte, a comunidade surda tem a assimilado e naturalizado. 
Hoje em dia a internet provê, para os surdos, um meio de comunicação que, apesar de requere um conhecimento mínimo da forma escrita da língua nacional, possibilita a interação típica da comunicação face-a-face sem a obrigatoriedade de compartilhar, das duas partes, a língua oral ou a língua sinalizada. A rapidez com que os surdos estão adotando todo tipo de comunicação eletrônica é prova de que ela está se naturalizando como forma de interação para uso dentro e fora da comunidade. (MCCLEARY, 2013, p. 19).

O dinamismo presente nessas interações comunicacionais desperta, ainda, possibilidades de inserções na educação formal e, portanto, processos de autonomia de si e de criticidade de mundo. O Metaverse, ciberespaço ou geografia virtual, carrega em si potencialidades diversas, do campo comercial até o educacional, contudo, ele por si só não é libertador (FRAGOSO, 2003) ou mesmo configurado como democrático, mesmo que possa dar pistas de acessos a exercícios de democracia. O reconhecimento da pessoa surda como sujeito e objeto na história deve ser uma provocação para a participação crítica em um mundo de maioria ouvinte a fim de que possa questionar posicionamentos excludentes, como no campo educacional.

\section{CONSIDERAÇÕES FINAIS}

A interação, sob a geografia virtual, para a comunidade surda é tão importante como para qualquer comunidade, contudo, inexistia autonomia efetiva pela falta de possibilidades de vontade e de instrumentos criados para que a comunicação ocorresse. O descompasso sobre acontecimentos cotidianos, a falta da garantia de acesso à educação formal e a dependência de pessoas intermediárias para a comunicação são alguns dos exemplos comuns que impedem uma perspectiva autônoma às pessoas surdas.

A utilização do recurso de telefones celulares, hoje não apenas com a função de ligação para a comunicação entre pessoas ouvintes, revela-se como instrumento de interação via aplicativos de redes sociais: whatsapp, facebook, instagram, entre outros que utilizam o envio de vídeos, ligação por vídeo capazes de possibilitar a escrita ou mesmo o comunicação por LIBRAS. A existência desses recursos não significa, a priori, acessar a educação formal, contudo, oferece possibilidades primeiro para outros olhares sobre o mundo ouvinte-centrado a fim de criticalo e conjurar uma consciência crítica no mundo.

Hoje a tecnologia auxilia a comunidade surda, facilitando a interação entre pessoas surdas e ouvintes, dando-lhes meios de experiências visuais, um dos sentidos mais provocados devido à ausência e/ou perda auditiva, dando-lhes uma memorização foto-espacial, capaz de possibilitar uma melhor percepção imagética de cores, locais, expressões visuais e corporais entre outras. Deste modo, a internet pode influenciar e ajudar no desenvolvimento da pessoa 
surda ao promover o rompimento entre a geografia local e a geografia virtual, haja visto a possibilidade de acessos a conteúdos descolados da presença física, como visitas a museus em outros países ou mesmo cursar uma graduação sem a necessidade do edifício físico, ainda que possamos questionar algumas posições do Estado frente à oferta e permanência de cursos de graduação.

\section{REFERÊNCIAS}

ALBUQUERQUE, Targélia de Souza. Pedagogia da autonomia: saberes necessários à prática educativa. OUZA, Ana Inês (org.). Paulo Freire: vida e obra. São Paulo: Expressão Popular, p. 203-245, 2015.

ANDRIOLI, Mary Grace Pereira; VIEIRA, Claudia Regina; CAMPOS, Sandra R.L. Uso das tecnologias digitais pelas pessoas surdas como meio de ampliação da cidadania. Encontro da Associação Brasileira de Pesquisadores em Educação Especial, 8, Anais [...]. Londrina: UEL, p. 1793-1804, 2013.

ARCOVERDE, Rossana Delmar de Lima. Tecnologias digitais: Novo espaço interativo na produção escrita dos surdos. Cad. Cedes, Campinas, vol. 26, n. 69, p. 251-267, maio/ago. 2006.

BRASIL. Lei Federal $N^{0}$ 10.436. Dispõe sobre a Língua Brasileira de Sinais - LIBRAS e dá outras providências. Brasília, 2002.

BRASIL. Decreto 5626, de 22 de dezembro de 2005. Regulamenta a Lei $\mathbf{n}^{0} 10.436$, de 24 de abril de 2002, que dispõe sobre a Língua Brasileira de Sinais - LIBRAS, e o art. 18 da Lei $n^{\circ}$ 10.098, de 19 de dezembro de 2000. Brasília, 2005.

COSTA, Maria Eugênia Belczak et al. Grupo Focal. In: DUARTE, Jorge et al. Métodos e Técnicas de Pesquisa em Comunicação. [S. 1.]: Atlas S.A., 2005.

FRAGOSO, Suely. Um e Muitos Ciberespaços. In: A. LEMES; P. CUNHA. Olhares sobre a Cibercultura. Porto Alegre, Sulina, p. 212-231, 2003.

FREIRE, Paulo. Pedagogia da esperança: um reencontro com a pedagogia do oprimido. Rio de Janeiro: Paz e Terra, 1992.

FREIRE, Paulo. Pedagogia da autonomia: saberes necessários à prática educativa. São Paulo: Paz e Terra, 1996.

GESSER, Audrei. LIBRAS? Que língua é essa?: Crenças e preconceitos em torno da língua de sinais e da realidade surda. São Paulo: Parábola Editorial, 2009. 
hooks, bell. Ensinando a transgredir: a educação como prática da liberdade. São Paulo: Editora WMF, 2017.

HONORA, Márcia. Inclusão educacional de alunos com surdez: concepção e alfabetização: ensino fundamental, $1^{\circ}$ ciclo. São Paulo: Cortez, 2014.

INSTITUTO DE LIBRAS. Aprenda LIBRAS com eficiência e rapidez. ISBN:978-85-60683$17-8$

LÉVY, Pierre. Cibercultura. São Paulo: Ed. 34, 1999.

MCCLEARY, Leland. Apresentação. In: VERGAMINI, Sabine Antonialli Arena (org.). Mãos fazendo história. Petrópolis: Editora Arara Azul, p. 12-23, 2003.

PERLIN, Gladis; SOUSA, Regina Maria. Política Inclusiva e Acesso ao Ensino Público Resistência e Espaços de Negociação. Revista Digital de Linguísticas, Córdoba, v. 7, ano 7, p. 52-71, set. 2015 .

SOUZA, Ana Inês. Educação e atualidade brasileira: a emersão do povo na história. SOUZA, Ana Inês (org.). Paulo Freire: vida e obra. São Paulo: Expressão Popular, p. 31-64, 2015.

STROBEL, Karin. As imagens do outro sobre a cultura surda. Florianópolis: Ed. da UFSC, 2018.

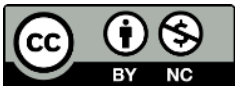

Este é um artigo de acesso aberto distribuído sob os termos da Licença Creative Commons Atribuição Não Comercial-Compartilha Igual (CC BYNC- 4.0), que permite uso, distribuição e reprodução para fins não comerciais, com a citação dos autores e da fonte original e sob a mesma licença. 